\title{
Soil Management by Cover Crops in Vineyards for Climate Change Adaptation ${ }^{\dagger}$
}

\author{
María José Marqués ${ }^{1, *}$, Ramón Bienes ${ }^{2}$ and Marta Ruiz-Colmenero ${ }^{3}$ \\ 1 Departamento Geología y Geoquímica. Universidad Autónoma de Madrid, 28049 Madrid, Spain \\ 2 Departamento de Investigación Aplicada y Extensión Agraria, Instituto Madrileño de Investigación y \\ Desarrollo Rural, Agrario y Alimentario, 28800 Alcalá de Henares, Spain; ramon.bienes@madrid.org \\ 3 Arid Ecology Lab, University of New South Wales, Sydney NSW 2052, Australia; m.ruizcolmenero@unsw.edu.au \\ * Correspondence: mariajose.marques@uam.es \\ † Presented at TERRAenVISION 2019, Barcelona, Spain, 2-7 September 2019.
}

Published: 19 December 2019

\begin{abstract}
The wine captures grapes variety nature and vinification techniques, but other aspects of soil, climate and terrain are equally important for the terroir expression as a whole. Soil supplies moisture, nitrogen, and minerals. Particularly nitrogen obtained through mineralization of soil organic matter and water uptake are crucial for grape yield, berry sugar, anthocyanin and tannin concentration, hence grape quality and vineyard profitability. Different climatic conditions, which are predicted for the future, can significantly modify this relationship between vines and soils. New climatic conditions under global warming predict higher temperatures, erratic and extreme rainfall events, and drought spells. These circumstances are particularly worrisome for typical thin soils of the Mediterranean environment. This study reports the effect of permanent grass cover in vineyards to maintain or increase soil organic matter and soil moisture. The influence of natural and simulated rainfalls on soils was studied. A comparison between minimum tillage (MT) and permanent grass cover crop (GC) of the temperate grass Brachypodium distachyon was done. Water infiltration, water holding capacity, organic carbon sequestration and protection from extreme events, were considered in a sloping vineyard located in the south of Madrid, Spain. The MT is the most widely used cultivation method in the area. The tradition supports this management practice to capture and preserve water in soils. It creates small depressions that accumulate water and eventually improves water infiltration. This effect was acknowledged in summer after recent MT cultivation; however, it was only short-lived as surface roughness declined after rainfalls. Especially, intense rainfall events left the surface of bare soil sealed. Consequently, the effects depend on the season of the year. In autumn, a rainy season of the year, MT failed to enhance infiltration. On the contrary, B. distachyon acted as a physical barrier, produced more infiltration ( $22 \%$ increase) and fewer particles detachment, due to increased soil structure stability and soil organic matter (50\% increase). The GC efficiently protected soil from high-intensity events (more than $2 \mathrm{~mm} \mathrm{min-1).} \mathrm{Besides,}$ soil moisture at $35 \mathrm{~cm}$ depth was enhanced with GC (9\% more than tillage). On average, soil moisture in GC was not significantly different from MT. These effects of GC on soil conditions created local microenvironmental conditions that can be considered advantageous as a climate change adaptation strategy, because they improved water balance, maintained a sustainable level of soil organic matter, therefore organic nitrogen, all these factors crucial for improving wine quality.
\end{abstract}

Keywords: soil erosion; wine; climate change

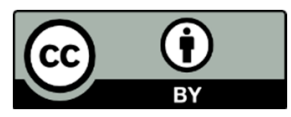

(c) 2019 by the authors. Licensee MDPI, Basel, Switzerland. This article is an open access article distributed under the terms and conditions of the Creative Commons Attribution (CC BY) license (http://creativecommons.org/licenses/by/4.0/). 